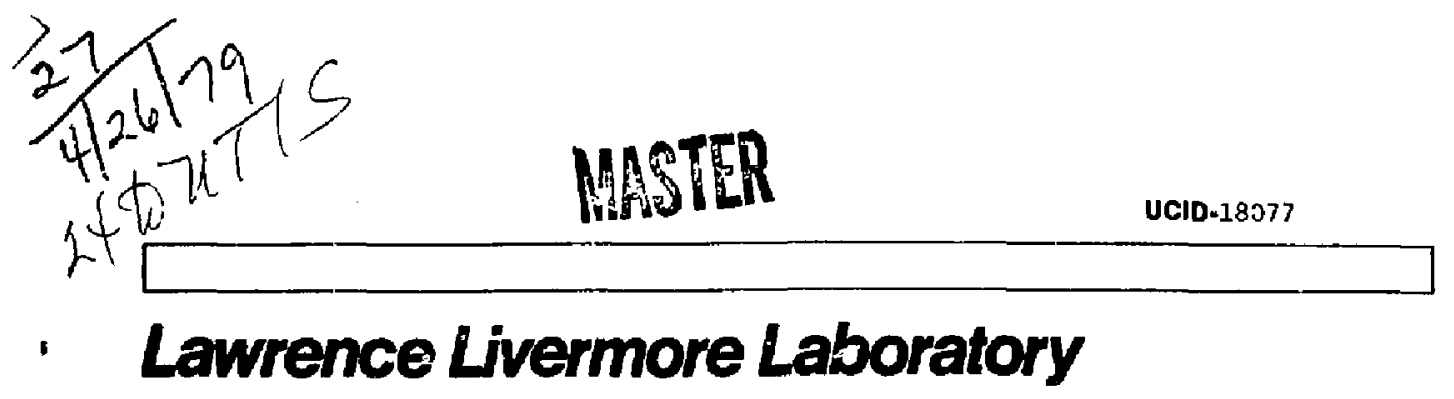

LARG:-AREA BORON AND CARBON SCATTERERS AND FILTERS

Thomas G. Woehrle

March 16, 1979

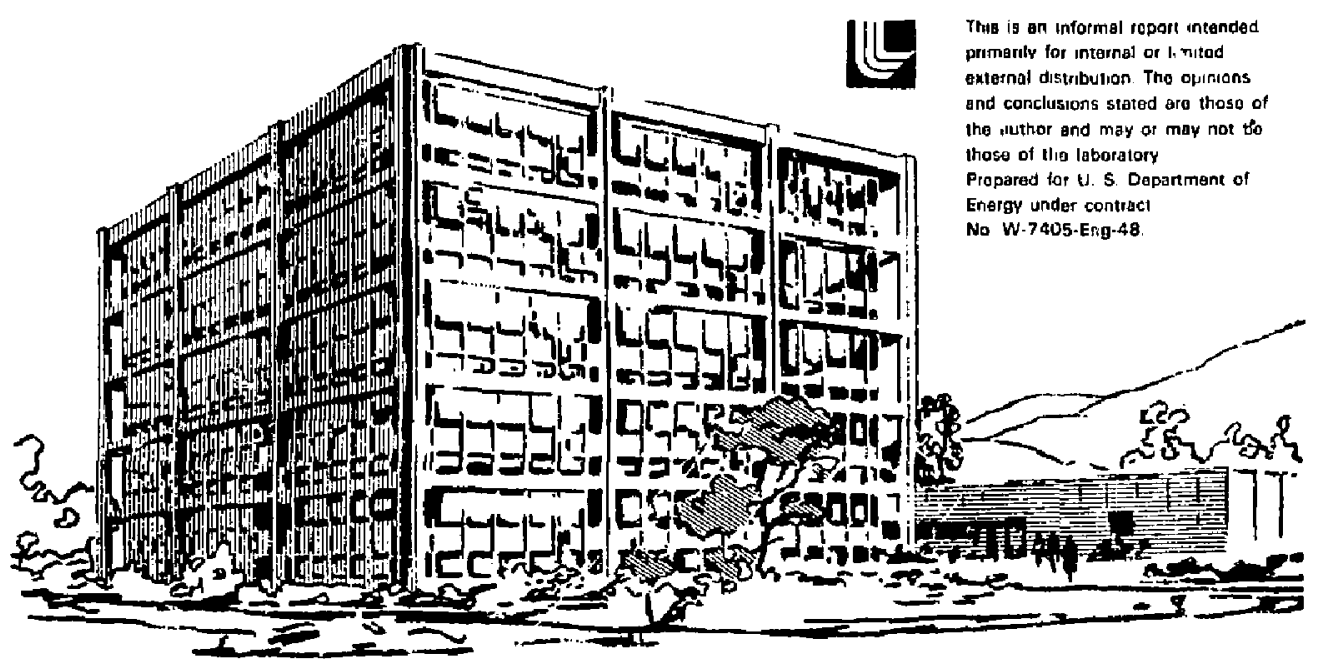




\section{LARGE-AREA BORON AND CARBON SCATTERERS AND FILTERS}

ABST'RACT'

We have successfully developed a technique for making large-area boron and carbon scatterers or filters for use on nuclear field experiments and in the ion accelerator/subkilovolt $x-r$ ay facility in the Lawrence tivermore Laboratory. We made these scatterers and filters by spraying a mixture of boron in ethyl alcohol or of carbon in isopropyl alcohol on a backing material of $0.00185-\mathrm{cm}$ polyethylene $\left(-\mathrm{CH}_{2} \mathrm{CH}_{2}-\right)$. In place of the polyethelene, any suitable backing material can be used.

\section{INTRODUCTION}

$\mathrm{X}$-ray scatterers that had a large area $\left(1760 \mathrm{~mm}^{2}\right.$ ) were reguired for a nuclear field experiment. The largest area of free-standing boron or carbon scatterers to date is $500 \mathrm{~mm}^{2}$.

We found that a variety of thicknesses could be obtained by spraying the appropriate substrate material onto a backing material. The thinnest possible substrate is when the scatterer is just opaque to light. Another method for producing large-area coated scatterers is to imnerse the scatterer in boron solution. 2 This methot allows for a much thinner substrate. However, in our particular case, we used the spraying application because the final scatterer holders are ceramic and were to be used as insulators. Also, we wanted to have the coatings on one side only.

\section{EQUIPMSNT FOR SPRAYING}

The spraying apparatus that we used was a standard Binks No. 059-10003 size "A" air brush. The air source was ary nitrogen pressurized between 20-35 psi. This source keeps both the water vapot and any other contaminants from entering the solution.

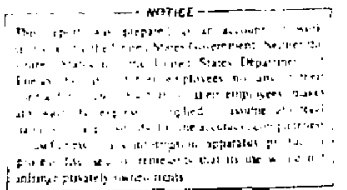


The boron and carbon solutions are easily obtainable from Acheson Industries. The original bocon solution was obtained from williamson and Masson. (They also Includeri information on where additional samples could be purchased.) The carbon solution came from a spray can of Acheson Aqua Dag. The carbon car also be obtained from jars of Aqua Dag thinned about 2 to I with isopropyl alcohol.

\section{PRELIMINARY PREPARATION}

Many steps are involved in preparing one of these scatterers. First, the backing material selectes should be thick enough so it can be laid down on a surface without breaking while still being attached to a holder. The backing material can be plastic, metal, or any other material that meets the experimenter's requirements.

Next, the backing material is attached to the holder of ting. The procedure that we follow is to glue the backing to the holder with carboline neoprene adhesive F-1 thinned with Carboline thinner 50-50. The gluing is done by laying the backing material on a flat, dust-free surface and then putting the holder on after it is coated with adhensive. These are then set aside to dry thoroughly.

The scatterer holders are weighed on a Sartorius No. 3400 Digital Analytical Balance. The masks for these particular scatterers were made of paper index cards with a hole cut about 2 to $5 \mathrm{~mm}$ smaller than the exposed backing material to eliminate the over-spray.

\section{SPRAYING}

For the spraying, we selected the size "A" nozzle Binks air brush after we experimented with three assorted size brushes. The "A" nozzle was the smailest of the three sizes and gave the finest line and smallest droplet size. With a fine line brush, one car, make many passes over the scatterer Instead of just one or two. This results in a more even, uniform covering. Figure 1 shows the directions and number of passes. If a large nozzle brush is used, the sprayed material will be splotchy and not uniform. 
Before spraying on the scatterers we planned to use, a number of practice scatterers were constructed using thick polyethylene. Because of the heaviness of this material, we ware able to reuge it many times. The practice holdets were weighed before and after the spraying to deternine the density of the substrate. When the desired density was reached, we used the actual holders.

Boron scatterers were not made for the fleld experinent. Only one practice boron scatterer was wade, and it had a thickness of $1.027 \times 10^{-3}$ $\mathrm{g} / \mathrm{cm}^{2}$. We were not striving at this time to obtain any specific thickness. However, for the carbon scatterer, we wanted a thickness of $2.326 \times 10^{-4}$ $g / \mathrm{cm}^{2} \pm 108$.

Table 1 shows the densitles we obtained on five carbon scatterers. After completing the five scatterers for a field experiment, we checked their trans. mission qualities in the 300-kV ion accelerator/subkilovolt $x-r$ ay facility. Table 2 lists the transmission resulta. A completed scatterer and holder is shown in Fig. 2 .

ADDITIONAL SCATPERERS

Since Octuber 1978, we have produced thinner scatterers. And as of March 1979. the thimest substrate used is 5000- and $10000-\AA$ Paraline N. These scatterers are being used by Jerry Gains on a scatterer evaltation experiment.

\section{CONCLUSIONS}

We are able to obtain specific substrate densities on carbon or boron scatterers and filte:s on backing materials as tin as $5000 \mathrm{~A}$.

\section{ACKNOWLEDGMENTS}

I appreciate the assistance of D. E. Nelson for his help in the preparation and gluing of the holders and scatterers and of D. Ernst for his guidance in the calibration of the scattererg. 


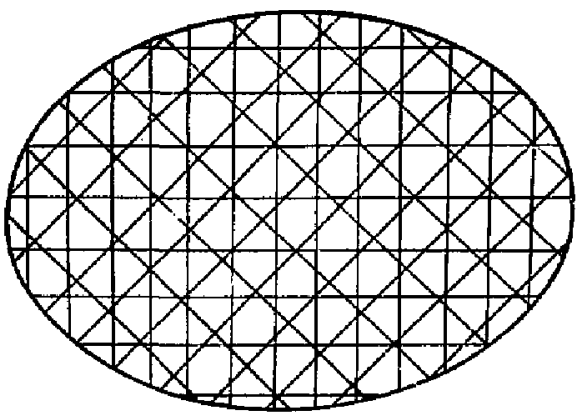

Legend:

- First pass

1 Second pass

Third pass

\section{Fourth pass}

Note: The passes must be kept close together. There is no set direction on the passes (left to right or up and down).

After all four passes have been completed, the procedure is to repeat the first or weigh the scatter to check the density.

FIG. 1. The unmasked area of the scatterer and the direction of the aifferent passes.

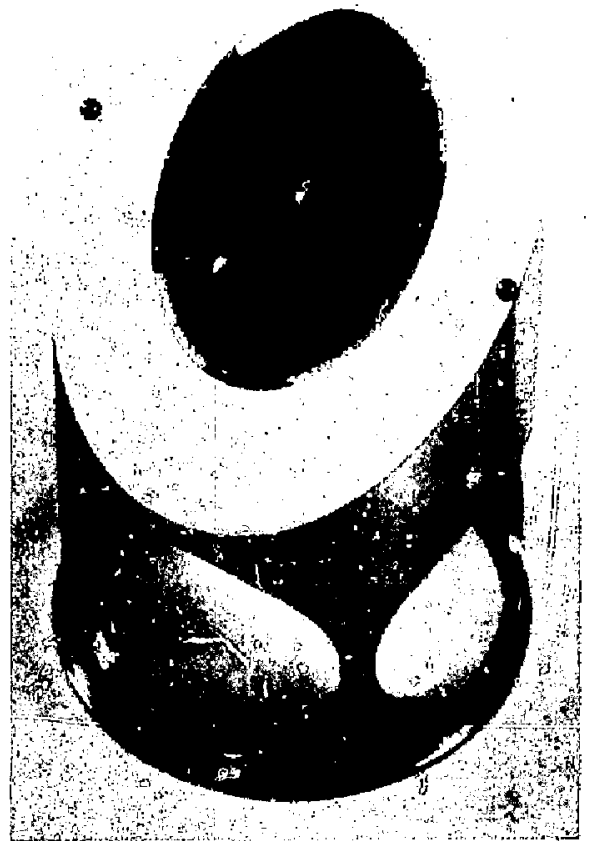

FIG. 2. Scatterer holder of $45^{\circ}$ angle with carbon and polyethylene mounted on a ceramic holder. 
TABLE 1. Densities of the five carbon scatterers.

\begin{tabular}{ccc}
\hline $\begin{array}{c}\text { Scatterer } \\
\text { No. }\end{array}$ & $\begin{array}{c}\text { Dengici } \\
\left(\times 10^{-4} \mathrm{~g} / \mathrm{cm}^{2}\right)\end{array}$ & $\begin{array}{c}\text { Percentage from } \\
\text { desired density }\end{array}$ \\
\hline 1 & 2.264 & -2.4 \\
2 & 2.093 & +28.8 \\
3 & 2.207 & -5 \\
4 & 2.163 & -6.8 \\
5 & 2.207 & -5 \\
\hline
\end{tabular}

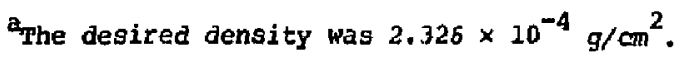

TABLE 2. Percentage of transmission two scatterers.

\begin{tabular}{|c|c|c|c|}
\hline $\begin{array}{c}\text { X-ray } \\
\text { energy } \\
\text { (ev) }\end{array}$ & $\begin{array}{l}\text { Scatterer No. } 2 \\
\text { on center }\end{array}$ & $\begin{array}{c}\text { Scatterer No. } 2 \\
+1.5738 \mathrm{~mm}\end{array}$ & $\begin{array}{c}\text { Scatterer No. } 2 \\
-1.5748 \mathrm{~mm}\end{array}$ \\
\hline $\mathrm{Cu}(832 \mathrm{ev})$ & 25.68 & $25 \%$ & 26.145 \\
\hline $\mathrm{Ni}(852 \mathrm{ev})$ & 27.38 & 16.58 & 27.88 \\
\hline & $\begin{array}{l}\text { Scatterer No. } 3 \\
\text { on center }\end{array}$ & $\begin{array}{c}\text { Scatterer Mo. } 3 \\
+1.5748 \mathrm{~mm}\end{array}$ & $\begin{array}{c}\text { Scatterer No. } 3 \\
-1.5748 \mathrm{~mm}\end{array}$ \\
\hline Cu $(932 \mathrm{eV})$ & 30.28 & 30.48 & 27.98 \\
\hline $\mathrm{Ni}(852 \mathrm{eV})$ & 218 & 21.28 & 19.48 \\
\hline
\end{tabular}

The first point is in the center of the foil and the other two are 1.5748 mum to each side of the center. 


\section{REFERENCES}

1. M. J. Rocke, Hroduction of Free-Standing Boron Films, Lawrence Livermoce Laboratory, Repl:. UCRL-79448 (1977) .

2. F. Williamson and C. W. Maxson, "Thin Films for X-Ray Astronomy," Rev. sci. Instrum. 46 (1) (1975\}.

RAC/als 